\title{
QUALITY OF Ni-Cr-Mo CASTING DENTAL ALLOYS IN TERMS OF Ni AND Mo CONTENTS CHANGING
}

\begin{abstract}
This paper presents results of microscopic examination and properties comparison of commercial Ni-Cr-Mo alloys (Remanium G-soft and Remanium CSe alloy) commonly used in dental laboratories. The study confirmed that a small change in the content of the basic components of the alloy, has a very large impact on the structural construction of alloy, and consequently on the properties of the alloy. The increased molybdenum content favors the segregation of the components and thus makes it possible to apply the $\mathrm{Ni}_{61} \mathrm{Cr}_{26} \mathrm{Mo}_{11} \mathrm{Si}_{1.5}(\mathrm{Fe}, \mathrm{Co}, \mathrm{Ce})_{\mathrm{x}}(\mathrm{x}<1)$ as a based material for prosthetics substructure veneered with ceramic material.
\end{abstract}

Key words: Ni-Cr-Mo alloy, dental restorations, Ni-alloy, microstructure

\section{Characteristics of Ni-Cr-Mo alloys}

The Ni-Cr alloys are widely used in dentistry, as a material for the preparation of prosthetic restorations, crowns, and in the form of bridges. One of the main factors, which often ultimately affects on the decision to choose Ni-Cr alloys, is their low price, but in the other hand it can be replace a lot more of their benefits. One of them is a good corrosion resistance, which results from the transition of metal in the passive state, it means that the surface of the alloy, which is most susceptible to external agents, including corrosive fluids easily covered with the oxide layer. In the case of Ni-Cr-Mo dental alloys are predominantly oxides of nickel, chromium and molybdenum, which effectively inhibit the access of substances to metal surfaces and thus reduce the rate of corrosion. Another factor in favor of the use of this alloy is their high elastic modulus. In dentistry, it is necessary, the formation of loadbearing structures, which be able to carry relatively large local stresses,

${ }^{1}$ Dr inż., Czestochowa University of Technology, Faculty of Management, Institute of Production Engineering, e-mail: klimt@wip.pcz.pl 
maintaining the designed shape, while having a relatively small thickness (KoRdASZ P., WOLANEK Z. 1983, MAJEWSKI S. 2000).

Due to the small amount of space that metal can take in the mouth, and additionally on its surface it must still be connected veneering materials, the dental technician is forced to create restoration (crowns and bridges) in this way to that their thickness in three areas: language, buccal and occlusal, does not exceed $0.3 \mathrm{~mm}$. Therefore, the Young's modulus, which, depending on the individual alloying elements varies around $E=170 \mathrm{GPa}$ and it is satisfactory. Another feature, which can include improve the restoration quality is hardness. Hardness of Ni-Cr-Mo alloys clearly exceeds the hardness of many, much more expensive alloys on the dental materials market. Mean values measured by the Vickers for $\mathrm{Ni}-\mathrm{Cr}-\mathrm{Mo}$ alloys is about $200 \mathrm{HV}$. This value is optimal, and processing of the restoration, using a milling cutter is not difficult, however, provides adequate structural stiffness of prosthetic (CIAPUTA T., CIAPUTA A. 2009, KoRdasZ P., WOLANEK Z. 1983, MAJEWSKi S. 2000).

The most common configuration, the percentage of the individual elements in the Ni-Cr alloys, is: nickel content between 60 and $80 \%$ at., while the amount of chromium is between 10-30 \% at.. Other additives are: molybdenum, tungsten and beryllium. Despite its many advantages, in many cases, reconstructive dentistry is forced to abandon this alloy because a very large number of people are allergic to nickel, which automatically disqualifies its use in the biological environment (CIAPUTA T., CiAPUTA A. 2009).

\section{The phase structure of Ni-Cr-Mo alloys}

Repeatedly carried out laboratory examinations on Ni-Cr-Mo alloys of, show their very good resistance to pitting, crevice and stress corrosion. Further, in a humid environment Ni-Cr-Mo alloys are especially electrochemical corrosion resistant (WWW.DENTERUM.DE, RADOMSKa K., KLIMECKA-TATAR D. 2013, ORLICKI R., KŁAPTOCZ B. 2003, RADOMSKA K., KliMECKA-TATAR D., JAGIELSKA-WIADEREK K. 


\section{3, TURChIAI P.E.A., KAUfMANB L., LiUC ZI-KUI 2006).}

However, despite these excellent properties of Ni-Cr-Mo alloys, decisions regarding their suitability for use as biomaterial is not only biotolerant but also biomechanical. About biomedical properties of NiCr-Mo alloys decide the thermodynamics and kinetics of phase transformation, as well as impurities and inclusions of other metals such as $\mathrm{Fe}, \mathrm{Co}, \mathrm{Ce}, \mathrm{Mn}, \mathrm{B}$ (impurities and inclusions directly affect to the long-term chemical stability and the proper mechanical properties).

On the basis of experimental data (TURCHIAI P.E.A., KAUFMANB L., LIUC ZI-KUI 2006) has been identified thermodynamic equilibrium phase system of Ni-Cr-Mo alloys composition similar to commercial alloy (named Remanium alloy), represented by two-dimensional Gibbs's triangles.

In the cases, it was found that above the $1250^{\circ} \mathrm{C}$ temperature, seems to be only one stable phase, $\gamma$ regular phase (face-center cubic - FCC). It is estimated that around $850^{\circ} \mathrm{C}$, the structure of an alloy containing $60 \% \mathrm{Ni}$, can be still single-phase but depending on the presence of alloying elements in the structure another phase can be formed. During cooling of the alloy from $1250^{\circ} \mathrm{C}$ temperature small inclusions in the form of carbides can be formed (carbides inclusions may adversely affect on the corrosion resistance). Carbides formation in this case is effect of structures aging (the precipitation of the finedispersion of intermetallic phases). We have also observed the formation of phases based on complex crystalline structures such as phase $\sigma, \mu$, or $\mathrm{P}$, having a significant impact on the overall mechanics of alloys and their corrosion resistance.

Research confirms that in equilibrium state, at low temperatures, in all tested varieties $\mathrm{Ni}-\mathrm{Cr}-\mathrm{Mo}$, should disclose the multiphase structure contains regular face-centered cubic structure $\gamma(\mathrm{Ni}$ rich), and one or two complex-type phase $\sigma$, $\mu$, or $\mathrm{P}$. Together with Ni-Cr-Mo alloy cooling $\gamma$-rich $\mathrm{Ni}$ phase is partly replaced by phases enriched in $\mathrm{Mo}$ and $\mathrm{Cr}$ (TURCHIAI P.E.A., KAUFMANB L., LIUC ZI-KUI 2006). 


\subsection{The commercial Ni-Cr-Mo alloy (Remanium G-soft)}

The Remanium G-soft is an alloy with chemical composition based on $\mathrm{Ni}$ and $\mathrm{Cr}$ with $5 \%$ at. molybdenum addition. The alloy composition comprises also approx. $26.5 \%$ at. $\mathrm{Cr}, 1.5 \%$ at. $\mathrm{Si}$, and the additions of manganese and boron does not exceed 1\% (Table 1). It is a specialpurpose alloy for casting of prosthetic structures such as crowns and bridges. For this alloy specially dedicated veneering material is composite. General properties of the alloy are shown in Table 2.

Table 1. The chemical composition of the Ni-Cr-Mo commercial alloys:

(a) Remanium G-soft, (b) Remanium CSe

\begin{tabular}{|c|c|c|c|}
\hline \multicolumn{2}{|c|}{ Remanium G-soft $(\boldsymbol{a})$} & \multicolumn{2}{c|}{ Remanium CSe $(\boldsymbol{b})$} \\
\hline Elements & \% at. & Elements & \% at. \\
\hline $\mathbf{N i}$ & 66 & $\mathbf{N i}$ & 61 \\
\hline $\mathbf{C r}$ & 26.5 & $\mathbf{C r}$ & 26 \\
\hline $\mathrm{Mo}$ & 5 & $\mathbf{M o}$ & 11 \\
\hline $\mathrm{Si}$ & 1.5 & $\mathbf{S i}$ & 1.5 \\
\hline $\mathrm{Mn}, \mathrm{B}$ & $<1$ & $\mathbf{F e}, \mathbf{C o}, \mathbf{C e}$ & $<1$ \\
\hline
\end{tabular}

Source: $w w w . d e n t e r u m . d e$

Recommended to thermal treatment of Remanium G-Soft are methods such as: melting using the gas burner, melting using an electric arc, and the use of an induction furnace. After passing the liquid state, the surface is always metallic, mirrored. Heating the alloy to the liquidus point temperature, the material is ideal for casting. Many induction furnaces, has the ability to force molten metal into a mold, using a pressure difference. The optimum pressure for Remanium G-Soft should be in the range 250-450 Mbar. As a result of various errors that can occur at various stages of the metal structure preparation, some parts could be unevenly casted or destroyed during the release of molding. The usage of Remanium alloy give the ability to do not repeat the entire procedure 
but use a welding technique. Welding of Remanium alloy should remain basically interchangeable, the two methods: using a laser welding or TIG (WWW.DENTERUM.DE).

Table 2. The basic properties of the Ni-Cr-Mo commercial alloys:

(a) Remanium G-soft, (b) Remanium CSe

\begin{tabular}{|c|c|c|}
\hline Properties & Remanium $\mathbf{G}$-soft (a) & Remanium CSe (b) \\
\hline yield strength, $\mathrm{MPa}$ & 310 & 340 \\
\hline tensile strength, $\mathrm{MPa}$ & 550 & 580 \\
\hline hardness, $\mathrm{HV} 10$ & 210 & 195 \\
\hline max. elongation, $\%$ & 8.00 & 15.00 \\
\hline elastic moduluj, $\mathrm{GPa}$ & 165 & 170 \\
\hline solidus point, $^{\circ} \mathrm{C}$ & 1210 & 1260 \\
\hline liquidus point, $^{\circ} \mathrm{C}$ & 1240 & 1350 \\
\hline standards & ISO 22674 & ISO 22674 \\
\hline
\end{tabular}

Source: $w w w . d e n t e r u m . d e$

\subsection{The commercial Ni-Cr-Mo alloy (Remanium CSe)}

Remanium CSe is an alloy close in composition to Remanium GSoft. The basis of this alloy is nickel, which was combined with $26 \%$ chromium and $11 \%$ molybdenum (Table 6.1). Although differences in components tend to be relatively small, they have an impact on individual parameters (Table 6.2). This alloy is used for casting crowns and bridges for ceramic veneering (WWW.DENTERUM.DE). As in the heat treatment of Remanium G-Soft, the Remanium CSe can be melted using three methods: melting with the gas burner, electric arc or induction melting furnace. When the alloy temperature increase to $1350^{\circ} \mathrm{C}$, the casting procedure can be proceed. In an induction furnace, uses the technology based on injection the pressure have to be in range 250-450Mbar.

The increased amount of molybdenum reduces the thermal expansion 
of the alloy, and the Remanium CSe alloy characterized with thermal expansion coefficient $14 \cdot 10^{-14} \mathrm{~K}$ can be combined with the ceramic material. According to the producer information, repeatedly raising its temperature to applying the various layers of porcelain, does not damage its structure. In oral cavity has a high stability, high-percentage content of chromium and molybdenum additive makes it resistant to corrosion. In its composition are not toxic beryllium impurities, which presence is very harmful to the human body (WWW.DENTERUM.DE).

\section{Classic method of the Ni-Cr-Mo alloy remelting - in prosthetic laboratories}

Preparation of metallic structures for prosthetic restoration associated with delivery of a suitable amount of heat to the alloy ingot to obtain the liquid alloy. For this purpose is most commonly used an electric arc (Volta's arc), which is produced by means of electric current. Through the use of thermal action of current, released by the approach of the two carbon electrodes to each other, the thermal treatment is carried out, the run time is controlled by increasing or decreasing at the same time of current intensity. Voltaic arc generating device consists a transformer, which primary purpose is to convert the alternating current (AC) with low intensity ratio $10 \mathrm{~A}$ and high-voltage $220 \mathrm{~V}$, direct to current with low voltage and high amperage 40V, $40 \mathrm{~A}$. Temperature generated between the electrodes may be up to $4000^{\circ} \mathrm{C}$. The disadvantage of using the alloy melting an electric arc generating device is alloy carburized effect, changing its chemical composition and consequently creating defects at the structural level, by increasing the amount of impurities (KORDASZ P., WOLANEK Z. 1983, MAJEWSKI S. 2000).

\section{The results of microscopic examination}

In Fig. 6.1 and 6.2 the images of two compared Ni-Cr-Mo alloys structure are shown. In Fig. 1 there are presented pictures of multiphase 
Remanium G-soft alloy structure, whereas in Fig. 2 structure of Remanium CSe alloy. As it was stated in previous research (RADOMSKA K., KLIMECKA-TATAR D. 2013, ORLICKI R., KŁAPTOCZ B. 2003, RADOMSKa K., KLIMECKA-TATAR D., JAGIELSKA-WiADEREK K. 2013), Turchiai P.E.A., Kaufmanb L., LiUC ZI-KuI 2006) the Remanium CSe alloy, which is designed for metal-ceramic structures is characterized by a dendritic structure. But in the other hand the structure of Remanium G-soft alloy is also semi-dendritic. However, the axes of dendrites growth are slightly less marked, and light-phase areas are much more similar to the globular. Increased additive content of molybdenum and a variable ratio of $\mathrm{Ni} / \mathrm{Cr}$ resulted that the interdendritic spaces occupy a much larger part of the alloy volume. It is known that both the dendrites composition and phase in interdendritic spaces is determined by the chemical composition of the melt and also casting technologies applied (e.g. higher temperature of alloy casting). The key role in terms of structure plays a segregation of major alloying elements ( $\mathrm{Ni}, \mathrm{Cr}, \mathrm{Mo})$.

In the structure of Ni-Cr-Mo dendrites are composed predominantly of $\gamma$ intermetallic phase (fcc) enriched in nickel. Increased molybdenum content in the alloy composition causes the strong segregation, and thus enrich the interdendritic areas in Mo (CHOLEWA M., GAWROŃSKI J., ET AL. 2004). Strong segregation of elements in structure during crystallization is promoted both by Mo higher content, but also by higher temperature of remelting. An important fact is that, in most Ni-Cr-Mo alloys, that the strong segregation of chromium is not observed, but $\mathrm{Cr}$ content is a bit lower in interdendritic spaces (PERRICONE M.J., DUPONT J.N. 2006). The presence of other impurities in the composition of the alloy such as beryllium, iron, nitrogen, carbon, even in small quantities, is also a pronounced effect on the structure morphology, the form of small precipitates also accumulate in the interdendritic spaces (KORNEVA A., Orlicka I., SzTwiertnia K. 2011., Perricone M.J., DuPont J.N., CIESLAK M.J. 2003, PERRICONE M.J., DUPONT J.N. 2002). 


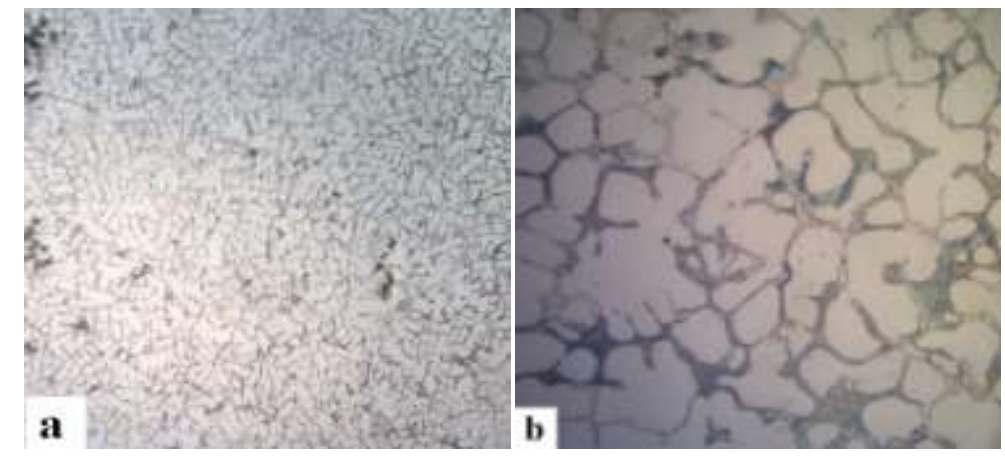

Fig. 1. The microstructure images of Remanium G-soft alloy. Source: own study

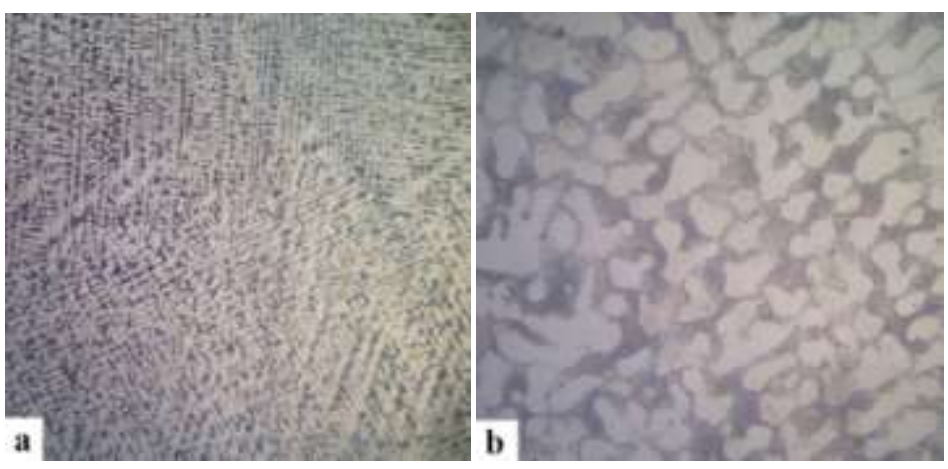

Fig. 2. The microstructure images of Remanium CSe alloy.

Source: own study

\section{Summary}

Based on observation of the Remanium G-soft and Remanium CSe alloy microstructue, after remelting process using Volta's arc, revealed significant structural differences between the Ni-Cr-Mo alloys with a similar chemical composition. Demonstrated the relationship between the presented images, describe important feature, which is the 
quantitative contribution of phase $\gamma$ (Ni-rich phase).

The Remanium CSe alloy, which is designed for metal-ceramic structures is characterized by a dendritic structure whereas the structure of Remanium G-soft, which is designed for metal-composite structures is semi-dendritic (the axes of dendrites growth are slightly less marked, and $\gamma$ phase (Ni-rich) areas are much more similar to the globular. Increased additive content of molybdenum and lower content of $\mathrm{Ni}$ resulted that the interdendritic are more dominant. The key role in terms of structure plays a segregation of major alloying elements ( $\mathrm{Ni}, \mathrm{Cr}, \mathrm{Mo})$.

Differences in the elements content and structural features of Remanium G-soft and Remanium CSe alloy confirm that the Remanium CSe, more than G-soft, suitable for use as a construction material for veneering ceramic. Repeated heating during the firing treatment of subsequent ceramics layers, lead to significant number of local melting which is beneficial to create a permanent connection metallic substructure with ceramic material.

\section{Bibliography}

1. Ciaputa T., Ciaputa A. 2009. Podstawy wykonawstwa prac protetycznych. ELAMED. Kraków

2. Data from the manufacturer $w w w$.denterum.de

3. RADOMSKA K., KLIMECKA-TATAR D. 2013. The effect of melting/casting method of $\mathrm{Ni}-\mathrm{Cr}$-Mo dental alloy on the corrosion resistance in ringer solution, Ochrona przed Korozją 11, s. 527-530.

4. ORLICKI R., KŁAPTOCZ B. 2003. Inżynieria Stomatologiczna Biomaterialy. Tom I nr 1, s. 3.

5. Radomska K., Klimecka-TataR D., Jagielska-WiadereK K. 2013. Dental alloy corrosion characteristics remanium $\mathrm{G}$ ( $\mathrm{Ni-Cr}-\mathrm{Mo})$ melting/casting by different techniques, Ochrona przed Korozją 57, s. 262268. 
6. Turchiai P.E.A., KaufManB L., Liuc ZI-Kui 2006. Modeling of $\mathrm{Ni}-\mathrm{Cr}-\mathrm{Mo}$ based alloys: Part I- phase stability. Computer Coupling of Phase Diagram and Thermochemistry 30. p.7-87.

7. Cholewa M., GaWroński J., ET AL. 2004. Podstawyprocesów metalurgicznych. Wyd. Politechniki Śląskiej. Gliwice.

8. PERricone M.J., DuPONT J.N. 2006. Effect of Composition on the Solidification Behavior of Several Ni-Cr-Mo and Fe-Ni-Cr-Mo Alloys. Met. And Trans. Vol. 37A, s. 1267-1280.

9. Korneva A., ORLICKA I., SZTWIERTNIA K. 2011. Mikrostruktura stomatologicznego stopu odlewniczego Ni-Cr-Mo Rodent. Inzynieria Stomatologiczna-Biomateriały 10. s. 12.

10. Perricone M.J., DuPont J.N., Cieslak M.J. 2003. Solidification of Hastelloy Alloys. Metall. Mater. Trans. A. 34, s.1127.

11. Perricone M.J. And DuPont J.N. 2002. Int. Conf. Joining of Advanced and Specialty Materials. J.E. Indacochea and J.N.V. DuPont, eds. ASM International. Materials Park.

12. Kordasz P., WOLANEK Z. 1983. Materiałoznawstwo protetycznostomatologiczne. PZWL. Warszawa.

13. MAJEWSKI S. 2000. Podstawy protetyki w praktyce lekarskiej i technice dentystycznej. Wyd. SZS-W. Kraków. 